\title{
ANALISIS LST, NDVI MENGGUNAKAN SATELIT LANDSAT 8 SERTA TREND SUHU UDARA DI KABUPATEN MAJALENGKA
}

\author{
Tia Pramudiyasari", Mangapul P. Tambunan, Rudy P. Tambunan, Masita D.M. Manessa \\ Jurusan Geografi, Fakultas Matematika dan IImu Pengetahuan Alam, Universitas Indonesia \\ *Penulis Korespondensi : tia.pramudiyasari@ui.ac.id
}

\begin{abstract}
Abstrak. Perkembangan suatu wilayah dan pertumbuhan jumlah penduduk pastinya diiringi oleh proses pembangunan. Perubahan tata guna lahan dari wilayah vegetasi menjadi wilayah non-vegetasi dapat mempengaruhi suhu permukaan pada suatu wilayah. Kabupaten Majalengka merupakan salah satu yang mengalami perkembangan dan pertumbuhan wilayah yang pesat. Tujuan penelitian ini adalah untuk mengeksplorasi dan membandingkan pola perubahan spasial dan temporal dari kerapatan vegetasi, Land Surface Temperature (LST) dan Suhu udara rata-rata harian Kabupaten Majalengka pada tahun 2015 dan 2019. Data yang digunakan berupa citra satelit Landsat 8 Band 4, 5 dan 10 pada tanggal 9 September 2015 dan 22 Oktober 2019 serta suhu udara observasi sepanjang tahun 2015 dan tahun 2019 dari Stasiun Meteorologi Kertajati. Hasil dari penelitian ini, didapati bahwa dalam lima tahun tersebut, kerapatan vegetasi kategori sangat rendah semakin meluas sebesar 13.262,27 ha. Secara spasial yang ditunjukkan oleh LST dan NDVI terlihat bahwa telah terjadi perubahan kerapatan vegetasi diiringi dengan bertambah luasnya LST $>35^{\circ} \mathrm{C}$ terutama di wilayah Kabupaten Majalengka bagian utara meliputi kecamatan Kartajati, Jatitujuh, Ligung, Sumberjaya, Kadipaten, Dawuan, Jatiwangi, Palasah, Panyingkiran, Majalengka dan Sukahaji.
\end{abstract}

Kata Kunci: : LST; NDVI; landsat; suhu udara; UHI

\begin{abstract}
The development of a region and population growth must be accompanied by a development process. Changes in land use from vegetated areas to non-vegetated areas can affect the surface temperature in an area. Majalengka Regency is one that has experienced rapid regional development and growth. The purpose of this study was to explore and compare the pattern of spatial and temporal changes of vegetation density, Land Surface Temperature (LST) and the daily average air temperature of Majalengka Regency in 2015 and 2019. The data used are Landsat 8 Band 4, 5 satellite imagery. and 10 on September 9, 2015 and October 22, 2019 and the observed air temperature throughout 2015 and 2019 from the Kertajati Meteorological Station. The results of this study, it was found that in those 5 years, the vegetation density of the very low category expanded by 13,262.27 ha. Spatially shown by LST and NDVI, it can be seen that there has been a change in vegetation density accompanied by an increase in LST >35 oC, especially in the northern part of Majalengka Regency covering the districts of Kartajati, Jati Tujuh, Ligung, Sumberjaya, Kadipaten, Dawuan, Jatiwangi, Palasah, Panyingkiran, Majalengka and Sukahaji.
\end{abstract}

Keywords: LST; NDVI; landsat; air temperature; UHI

\section{PENDAHULUAN}

Melansir informasi Intergovernmental Panel on Climate Change (IPCC), bahwa suhu gabungan permukaan laut dan daratan rata-rata global yang dihitung dengan tren linier menunjukkan pemanasan $0,85(0,65$ hingga 1,06$){ }^{\circ} \mathrm{C}$ selama periode 1880 hingga 2012. Suhu global telah mengalami peningkatan antara rata-rata periode 1850-1900 dan periode 2003-2012 adalah 0,78 (0,72 hingga $0,85)^{\circ} \mathrm{C}$. Dengan laju pemanasan selama 1998-2012 adalah $0,05(-0,05$ hingga 0,15$){ }^{\circ} \mathrm{C}$ per dekade (IPCC, 2014).
Dampak dari pemanasan global tersebut bisa menyebabkan perubahan iklim dalam waktu tertentu yang membuat perubahan atmosfer secara global. Salah satu akibat dari perubahan itu merupakan meningkatnya temperatur atau suhu udara. Akibat lain yang ditimbulkan dengan kenaikan temperatur tersebut antara lain perubahan pola hujan serta salju yang jatuh ke permukaan, cuaca dan musim, dan naiknya permukaan air laut. Perihal ini dapat terjadi langsung ataupun tidak langsung sebagai akibat dari aktivitas manusia (Utomo dkk., 2017). 
Meningkatnya jumlah penduduk pastinya pula diiringi dengan proses pembangunan . Konversi tata guna lahan dari wilayah vegetasi yang kemudian menjadi wilayah non vegetasi, semacam pemukiman misalnya dapat mempengaruhi suhu permukaan pada wilayah tersebut. Tidak hanya itu, kondisi tersebut baik secara langsung ataupun tidak langsung dapat juga mempengaruhi kejadian pemanasan global yang terjadi.

Kabupaten Majalengka pada tahun 2019, mempunyai jumlah penduduk 1.205.034 jiwa dengan luas wilayah $1.204,24 \mathrm{~km}^{2}$ serta rata-rata kepadatan penduduk 1.000,66 jiwa/km². Secara geografis Kabupaten Majalengka terletak di bagian timur Provinsi Jawa Barat. Keadaan topografi Kabupaten Majalengka, bagian utara daerah kabupaten ini merupakan dataran rendah dan di bagian selatan berbentuk pegunungan (Badan Pusat Statistik, 2020). Saat ini Majalengka mengalami pertumbuhan serta perkembangan ekonomi yang sangat pesat. Hadirnya Lapangan terbang Internasional Kertajati, hadirnya ruas jalur toll serta berdirinya pabrik pabrik skala besar memberikan pengaruh yang signifikan untuk Majalengka baik itu terhadap perkonomian warga ataupun dampak terhadap lingkungan.

Penelitian tentang LST (Land Surface Temperature) dan NDVI (Normalized Difference Vegetation Index) menggunakan citra citra satelit Landsat dirasa perlu diperhatikan dan dilakukan karena dapat menunjang proses perencanaan, penggunaan serta pemanfaatan lahan. Pemanfaatan penginderaan jauh Landsat memiliki keunggulan dari sisi kontinuitas dan distribusi spasial data.

Oleh sebab itu dilakukan penelitian secara kualitatif yakni keruangan atau spasial dan juga secara kuantitatif atau perhitungan statistik terhadap LST, NDVI dan juga suhu udara rata-rata harian Kabupaten Majalengka. Penelitian ini bertujuan mengeksplorasi dan membandingkan pola perubahan spasial dan temporal dari kerapatan vegetasi, Land Surface Temperature (LST) dan Suhu udara rata-rata harian Kabupaten Majalengka pada tahun 2015 dan 2019.

\section{METODOLOGI}

Beberapa data yang digunakan dalam penelitian ini diantaranya menggunakan data citra Landsat 8 OLI yang diunduh dari website USGS untuk tanggal 09 September 2015 dan 22 Oktober 2019, Suhu udara rata - rata harian dari Stasiun Meteorologi Kertajati Majalengka tahun 2015 dan 2019 dan Peta Administrasi Kabupaten Majalengka.

Penelitian ini terdiri dari beberapa tahapan diantaranya adalah sebagai berikut :

a. Klasifikasi NDVI (Normalized Difference Vegetation Index). Dalam mengolah NDVI digunakan data citra Landsat 8 band infrared dan NIR yakni band 4 dan 5, kemudian menggunakan rumus :

$$
N D V I=\frac{(\text { Band } 5-\text { Band } 4)}{(\text { Band } 5+\text { Band } 4)}
$$

Tabel 1. Klasifikasi Nilai NDVI

\begin{tabular}{ccc}
\hline Kelas & NDVI & Keterangan \\
\hline 1 & -1 s/d -0,03 & Lahan tidak bervegetasi \\
\hline 2 & $-0,03$ s/d 0,15 & Kehijauan sangat rendah \\
\hline 3 & 0,15 s/d 0,25 & Kehijauan rendah \\
\hline 4 & 0,26 s/d 0,35 & Kehijauan sedang \\
\hline 5 & 0,36 s/d 1,00 & Kehijauan tinggi \\
\hline
\end{tabular}

b. Klasifikasi Land Surface Temperature (LST), dalam proses pengolahan suhu permukaan ini data yang digunakan adalah data citra satelit Landsat 8 , band yang digunakan adalah band TIRS. Untuk Landsat 8 sendiri, band TIRS nya terdapat pada band 10 . Kemudian menggunakan rumus :

$$
L S T=\frac{\mathrm{BT}}{1+\left(\left(\frac{\lambda B T}{c 2}\right) \ln \mathrm{e} \lambda\right)}
$$

c. Menganalisis hubungan LST dengan perubahan tutupan lahan dan trend suhu udara di Kabupaten Majalengka tahun 2015 dan 2019. 


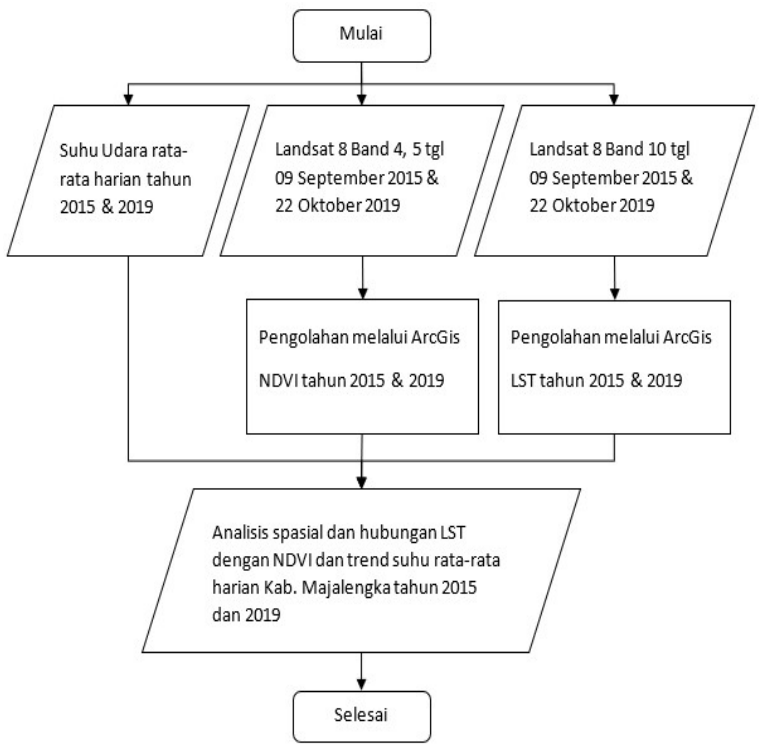

Gambar 1. Alur Penelitian

\section{HASIL DAN PEMBAHASAN}

Setelah dilakukan proses pengolahan, didapatkan distribusi NDVI dan LST Kabupaten majalengka tahun 2015 dan 2019 yang kemudian dapat dianalisis dan dibandingkan.

Berdasarkan Gambar 2 dan Tabel 2 perbandingan kerapatan vegetasi Kabupaten Majalengka tahun 2015 dan 2019, dapat dilihat bahwa dalam jangka waktu 5 tahun yakni dari tahun 2015 hingga 2019 wilayah Kabupaten Majalengka dengan kategori kerapatan vegetasi sangat rendah semakin bertambah seluas kurang lebih 13.262,27 ha dan kerapatan vegetasi rendahnya mengalami penurunan seluas $11.577,75$ ha. Sementara kerapatan sedang bertambah seluas $6.922,87$ ha dan kerapatan tingginya berkurang seluas $8.607,73$ ha.

Dari Tabel 3 dan Tabel 4 dapat dilihat bahwa sebagian besar kategori kerapatan vegetasi sangat rendah di Kabupaten Majalengka terus meluas hingga tahun 2019, terutama yang tampak signifikan yakni di wilayah kecamatan Kertajati, Jatitujuh, Talaga, Dawuan dan Majalengka. Begitu pula dengan luasan kerapatan vegetasi tinggi, sebagian besar wilayah kecamatan di Kabupaten Majalengka mengalami penurunan hingga tahun 2019, terutama yang tampak signifikan yakni di wilayah Kecamatan Argaura, Cikijing, Talaga, Bantarujeg dan Lemahsugih. Artinya hampir di sebagian besar wilayah Kabupaten Majalengka jika dilihat dari nilai
NDVI tahun 2015 hingga tahun 2019 mengalami penurunan luasan kerapatan vegetasi hijau.

Tabel 2. Perbandingan Kerapatan Vegetasi Kabupaten Majalengka Tahun 2015 dan 2019

\begin{tabular}{ccccc}
\hline \multirow{2}{*}{ No. } & \multirow{2}{*}{$\begin{array}{c}\text { Kerapatan } \\
\text { Vegetasi }\end{array}$} & \multicolumn{2}{c}{ Luas (ha) } & $\begin{array}{c}\text { Perubahan } \\
\text { (ha) }\end{array}$ \\
\cline { 3 - 5 } & Sangat & $\mathbf{2 0 1 5}$ & $\mathbf{2 0 1 9}$ & \\
\hline 1 & $\begin{array}{l}\text { Rendah } \\
\text { Rendah }\end{array}$ & $53.347,81$ & $41.770,06$ & -11.577 .75 \\
\hline 2 & Rend,82 & $31.709,09$ & $13.262,27$ \\
\hline 3 & Sedang & $34.762,73$ & $41.685,60$ & $6.922,87$ \\
\hline 4 & Tinggi & $24.977,50$ & $16.369,78$ & $-8.607,73$ \\
\hline
\end{tabular}

NDVI Kabupaten Majalengka Tahun 2015

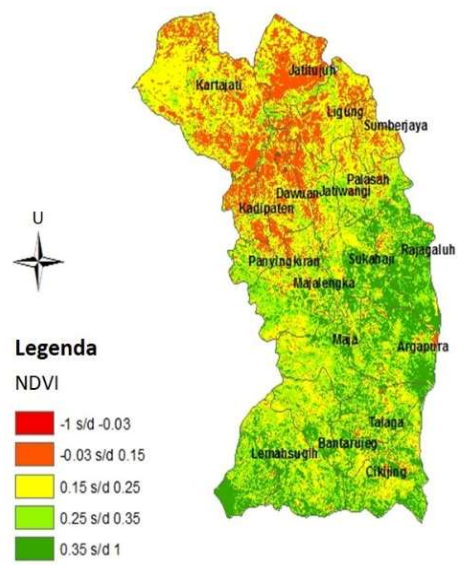

(a)

NDVI Kabupaten Majalengka Tahun 2019

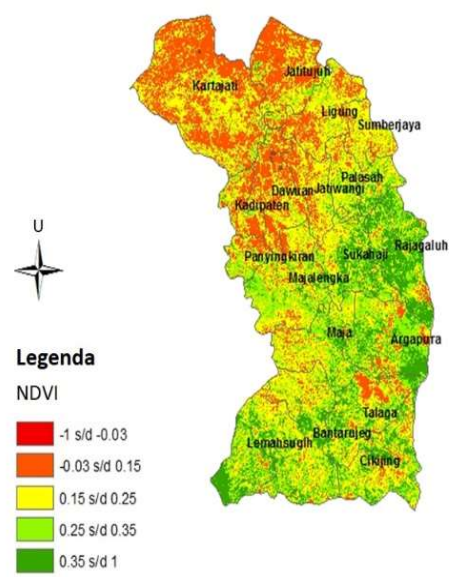

(b)

Gambar 2. NDVI Kabupaten Majalengka (a) Tahun 2015 dan (b) Tahun 2019

Tabel 3. NDVI di Kabupaten Majalengka Tahun 2015

\begin{tabular}{ccccc}
\hline \multirow{2}{*}{ Kecamatan } & \multicolumn{4}{c}{ Luas (ha) } \\
\cline { 2 - 5 } & $\begin{array}{c}\text { Kehijauan } \\
\text { Sangat } \\
\text { Rendah }\end{array}$ & $\begin{array}{c}\text { Kehijauan } \\
\text { Rendah }\end{array}$ & $\begin{array}{c}\text { Kehijauan } \\
\text { Sedang }\end{array}$ & $\begin{array}{c}\text { Kehijauan } \\
\text { Tinggi }\end{array}$ \\
\hline Argapura & 257,88 & $1.644,92$ & $3.102,65$ & $3.350,43$ \\
\hline
\end{tabular}




\begin{tabular}{crrrr}
\hline Bantarujeg & 133,60 & $3.668,71$ & 4189.71 & 2619.55 \\
\hline Cikijing & 260,25 & $2.310,21$ & 2595.88 & 2540.65 \\
\hline Dawuan & $2.472,39$ & $3.179,45$ & 705.16 & 84.99 \\
\hline Jatitujuh & $3.504,11$ & $3.702,85$ & 841.88 & 74.65 \\
\hline Jatiwangi & $1.289,44$ & $3.293,60$ & 1776.74 & 410.81 \\
\hline Kadipaten & $1.205,27$ & $1.195,71$ & 373.30 & 28.48 \\
\hline Kartajati & $5.096,53$ & $12.504,25$ & 1368.61 & 157.76 \\
\hline Lemahsugih & 72,44 & $1.985,52$ & 2875.62 & 3201.15 \\
\hline Ligung & $1.798,73$ & $3.641,00$ & 714.07 & 15.95 \\
\hline Maja & 110,96 & $2.422,93$ & 3007.58 & 1474.56 \\
\hline Majalengka & 520,79 & $3.809,81$ & 3621.56 & 1200.11 \\
\hline Palasah & 251,53 & $1.730,01$ & 926.26 & 117.05 \\
\hline Panyingkiran & 221,95 & 850,49 & 907.27 & 229.20 \\
\hline Rajagaluh & 183,51 & $1.045,60$ & 2365.12 & 4245.87 \\
\hline Sukahaji & 128,51 & $1.849,32$ & 2189.61 & 2565.95 \\
\hline Sumberjaya & 768,33 & $2.148,02$ & 400.67 & 11.73 \\
\hline Talaga & 170,35 & $2.353,76$ & 2785.95 & 2639.78 \\
\hline & & & &
\end{tabular}

Tabel 4. NDVI di Kabupaten Majalengka Tahun 2019

\begin{tabular}{crrrr}
\hline \multirow{2}{*}{ Kecamatan } & \multicolumn{4}{c}{ Luas (ha) } \\
\cline { 2 - 5 } & $\begin{array}{c}\text { Kehijauan } \\
\text { Sangat } \\
\text { Rendah }\end{array}$ & $\begin{array}{c}\text { Kehijauan } \\
\text { Rendah }\end{array}$ & $\begin{array}{c}\text { Kehijauan } \\
\text { Sedang }\end{array}$ & $\begin{array}{c}\text { Kehijauan } \\
\text { Tinggi }\end{array}$ \\
\hline Argapura & 864.44 & 1335.09 & 4313.17 & 1843.85 \\
\hline Bantarujeg & 743.53 & 3626.85 & 4570.57 & 1670.71 \\
\hline Cikijing & 851.62 & 2174.99 & 3247.52 & 1433.47 \\
\hline Dawuan & 3339.45 & 2258.44 & 810.61 & 33.48 \\
\hline Jatitujuh & 4581.08 & 2396.41 & 1090.45 & 55.56 \\
\hline Jatiwangi & 1596.05 & 2821.05 & 1874.85 & 478.59 \\
\hline Kadipaten & 1278.24 & 916.17 & 599.37 & 9.22 \\
\hline Kartajati & 10589.78 & 7185.22 & 1338.82 & 13.11 \\
\hline Lemahsugih & 389.54 & 1972.35 & 3463.22 & 2309.16 \\
\hline Ligung & 2091.66 & 2914.00 & 1145.39 & 18.37 \\
\hline Maja & 688.92 & 2369.23 & 3199.55 & 758.45 \\
\hline Majalengka & 1203.67 & 3186.43 & 4232.43 & 529.93 \\
\hline Palasah & 327.05 & 1448.48 & 1055.88 & 193.44 \\
\hline Panyingkiran & 602.07 & 639.39 & 906.03 & 61.40 \\
\hline Rajagaluh & 355.05 & 822.56 & 3058.40 & 3603.69 \\
\hline Sukahaji & 329.91 & 1758.20 & 2956.96 & 1688.31 \\
\hline Sumberjaya & 654.38 & 1924.74 & 732.17 & 17.14 \\
\hline Talaga & 1219.04 & 2009.14 & 3075.20 & 1646.47 \\
\hline & & & &
\end{tabular}

Tabel 5. LST Kab. Majalengka Tahun 2015 dan 2019

\begin{tabular}{ccccc}
\hline \multirow{2}{*}{ No. } & Suhu $\left({ }^{\circ} \mathrm{C}\right)$ & \multicolumn{2}{c}{ Luas } & $\begin{array}{c}\text { Perubahan } \\
\text { (ha) }\end{array}$ \\
\cline { 2 - 4 } & $\mathbf{2 0 1 5}$ & $\mathbf{2 0 1 9}$ & -28454.87 \\
\hline 1 & $<30$ & 55539.52 & 27084.66 & -22826.10 \\
\hline 2 & $30-35$ & 71412.99 & 48586.89 & 51280.06 \\
\hline 3 & $>35$ & 4581.03 & 55861.09 & \\
\hline
\end{tabular}

\section{LST Kabupaten Majalengka Tahun 2015}

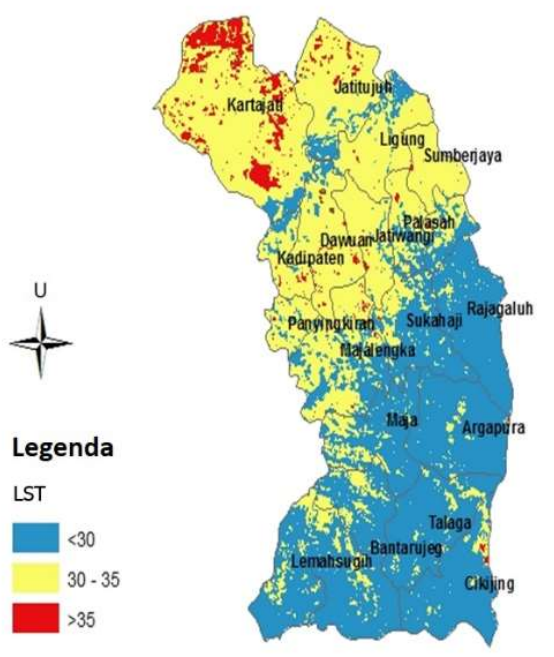

(a)

LST Kabupaten Majalengka Tahun 2019

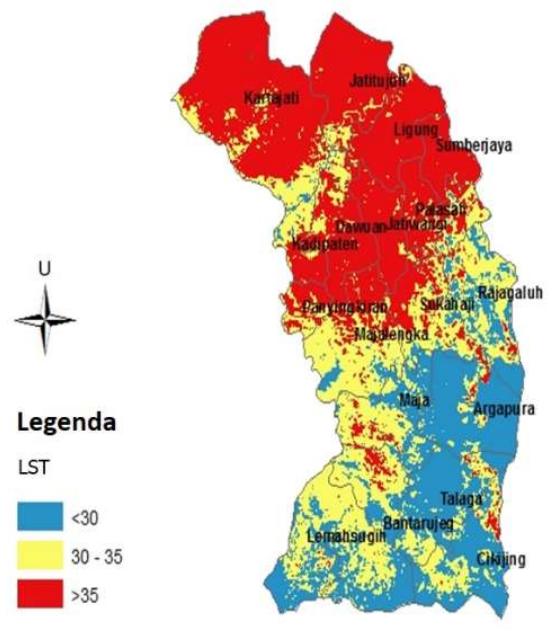

(b)

Gambar 3. LST Kabupaten Majalengka (a) Tahun 2015 dan (b) Tahun 2019

Berdasarkan Gambar 3 serta Tabel 5, perbandingan LST tahun 2015 dan 2019 Kabupaten Majalengka didapati bahwa terjadi perubahan luasan wilayah dengan suhu $<30^{\circ} \mathrm{C}$ yakni berkurang sebesar 28.454,87 ha, sementara terjadi penambahan luasan wilayah $>35{ }^{\circ} \mathrm{C}$ sebesar $51.280,06$ ha. Jika dilihat secara spasial, terlihat bahwa terjadi peningkatan LST yang signifikan terutama di wilayah Kabupaten Majalengka bagian utara meliputi kecamatan Kartajati, Jatitujuh, Ligung, Sumberjaya, Kadipaten, Dawuan, Jatiwangi, Palasah, Panyingkiran, Majalengka dan Sukahaji. 


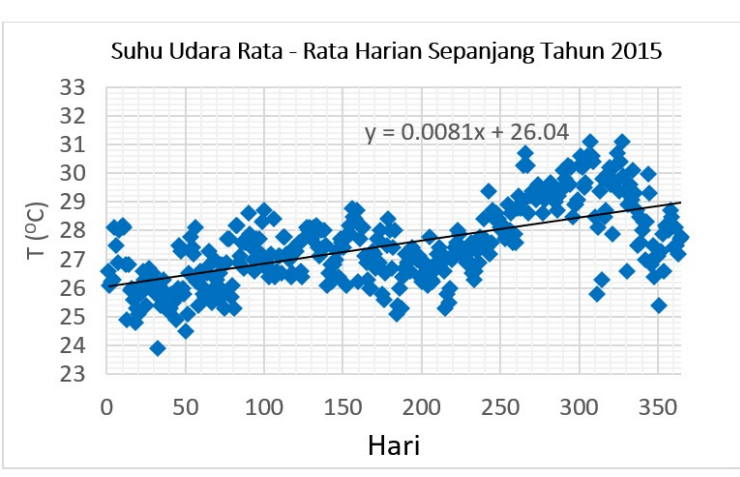

Gambar 4. Trend suhu udara rata- rata harian sepanjang Tahun 2015

Dari Gambar 4, dapat dilihat bahwa suhu udara rata - rata sepanjang tahun 2015 yang didapatkan dari Stasiun Meteorologi Kertajati BMKG dalam sepanjang tahun 2015 mengalami trend positif dengan persamaan $y=0.0081 x+26.04$, menunjukkan bahwa terjadi kenaikan suhu rata-rata sebesar $0,0081{ }^{\circ} \mathrm{C}$ tiap harinya. Berdasarkan data, jika dilihat berdasarkan suhu rata - rata harian didapati suhu terendah $23,9^{\circ} \mathrm{C}$ dan suhu tertinggi $31,1^{\circ} \mathrm{C}$.

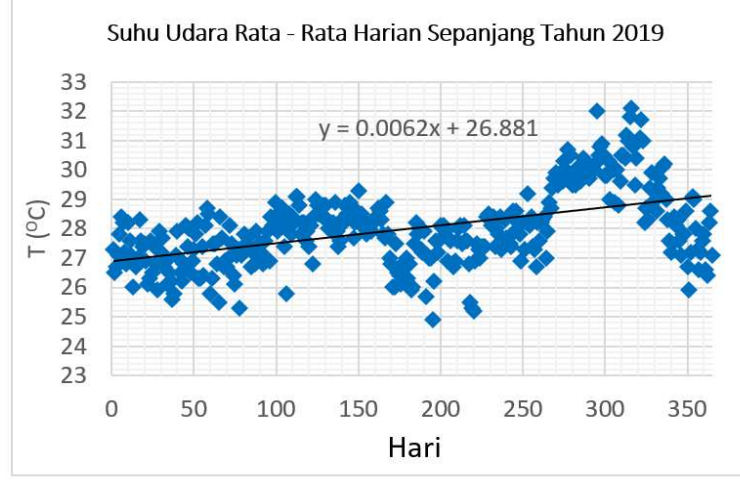

Gambar 5. Trend suhu udara rata- rata harian sepanjang Tahun 2019

Dari Gambar 5, dapat dilihat bahwa suhu udara rata - rata sepanjang tahun 2019 mengalami trend positif dengan persamaan $y=0,0062 x+26,881$, menunjukkan bahwa terjadi kenaikan suhu rata-rata sebesar $0,0062{ }^{\circ} \mathrm{C}$ tiap harinya. Berdasarkan data suhu udara rata - rata harian, didapatkan bahwa suhu udara terendah adalah $24,9{ }^{\circ} \mathrm{C}$ dan suhu tertinggi $32,1^{\circ} \mathrm{C}$ terjadi kenaikan suhu udara sebesar $1{ }^{\circ} \mathrm{C}$ jika dibandingkan dengan tahun 2015.

Pada Gambar 6 dapat dilihat bahwa LST dan NDVI Kabupaten Majalengka di tahun 2015 memiliki koefisien determinasi sebesar R2 $=0,477$, yang artinya bahwa variabel bebas NDVI mampu menjelaskan varians dari variable terikat LST sebesar $47,7 \%$, dan memiliki korelasi yang kuat $R=-0,69$ yang artinya NDVI dan LST memiliki korelasi negatif yang kuat dimana semakin besar nilai NDVI maka nilai LST semakin rendah. Pada Gambar 7, dapat dilihat bahwa LST dan NDVI Kabupaten Majalengka di tahun 2019 memiliki koefisien determinasi sebesar $\mathrm{R} 2=0,368$, yang artinya bahwa variabel bebas NDVI mampu menjelaskan varians dari variable terikat LST sebesar $36,8 \%$, dan memiliki korelasi yang kuat $R=-$ 0,607 yang artinya NDVI dan LST memiliki korelasi negatif yang kuat dimana semakin besar nilai NDVI maka nilai LST semakin rendah. Namun jika dilihat dengan seksama di Gambar 6 dan Gambar 7, terdapat beberapa titik wilayah yang tidak berlaku kondisi tersebut, yakni walaupun memiliki NDVI rendah namun juga memilki LST rendah, dan hal tersebut perlu dikaji lebih lanjut.

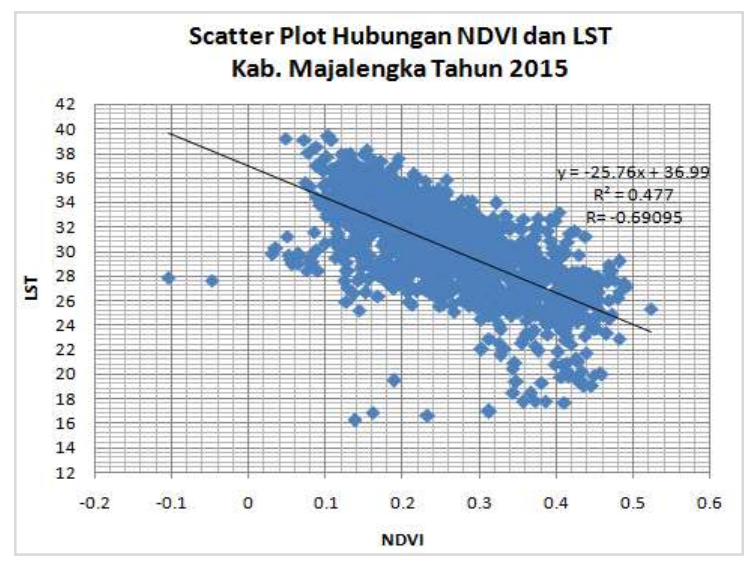

Gambar 6. Scatterplot NDVI vs LST Kabupaten Maialengka Tahun 2015

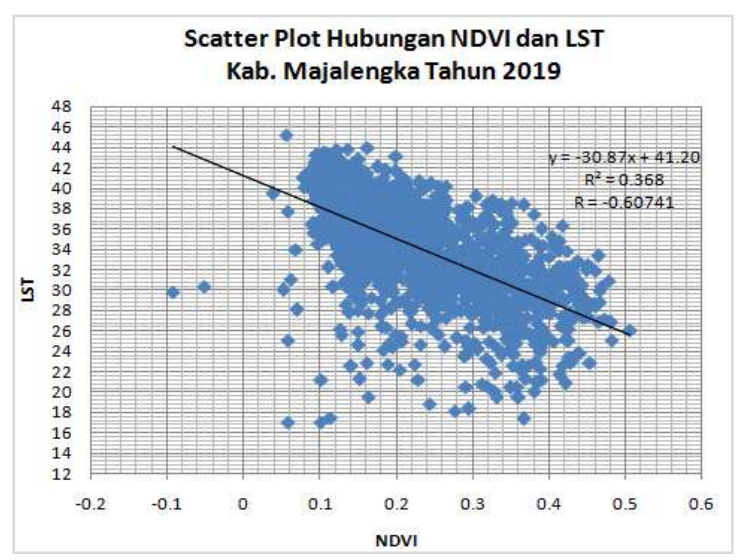

Gambar 7. Scatterplot LST vs NDVI Kabupaten Majalengka Tahun 2019 
Dari Gambar 6 dan Gambar 7 dapat dilihat bahwa semakin besar nilai NDVI maka LST akan cenderung menurun. Hal ini menunjukkan bahwa kerapatan vegetasi di suatu wilayah dapat berpengaruh dalam mengontrol tingkat suhu udara permukaan di wilayah tersebut terutama di wilayah - wilayah perkotaan, untuk meminimalkan efek dari urban heat island.

\section{PENUTUP}

\section{Simpulan dan Saran}

Dari penelitian yang dilakukan, dapat disimpulkan hal-hal sebagai berikut:

1. Telah terjadi perubahan kerapatan vegetasi diiringi dengan bertambah luasnya wilayah dengan LST $>35{ }^{\circ} \mathrm{C}$ dari tahun 2015 hingga 2019 terutama di wilayah Kabupaten Majalengka bagian utara, meliputi kecamatan Kartajati, Jatitujuh, Ligung, Sumberjaya, Kadipaten, Dawuan, Jatiwangi, Palasah, Panyingkiran, Majalengka dan Sukahaji.

2. Korelasi antara LST dan NDVI Kabupaten Majalengka di tahun 2015 dan 2019 memiliki korelasi negatif yang kuat, yang menunjukkan semakan rendah nilai NDVI maka nilai LST akan semakin tinggi. Suhu udara rata-rata harian sepanjang tahun 2015 dan 2019 juga menunjukkan trend yang positif yakni kecenderungan meningkat sepanjang tahun tersebut.

Kedepannya perlu dilakukan penelitian lebih lanjut untuk mengkaji hubungannya terhadap UHI (Urban Heat Island) dan perubahan iklim.

\section{Ucapan Terima Kasih}

Penulis menyampaikan ucapan terima kasih kepada seluruh civitas akademika Jurusan Geografi, FMIPA, Universitas Indonesia yang telah mendukung sehingga penelitian ini bisa terselesaikan.

\section{DAFTAR PUSTAKA}

Ali, M., Hadi, S. dan Sulistyantara, B. (2016), "Study on Land Cover Change of Ciliwung Downstream Watershed with Spatial Dynamic Approach", Procedia
- Social and Behavioral Sciences, Vol.227, hal. 52-59. http://doi.org/10.1016/j.sbspro.2016.06.042.

Anputhas, M., Janmaat, J. (John) A., Nichol, C.F. dan Wei, X. (Adam) (2016), "Modelling Spatial Association in Pattern Based Land Use Simulation Models", Journal of Environmental Management, Vol.181, hal. 465476. http://doi.org/10.1016/j.jenvman.2016.06.034.

Badan Pusat Statistik (2020), Kabupaten Majalengka dalam Angka. Diambil dari https://majalengkakab.bps.go.id/publication/2020/0 4/27/614dbdc2d9a288e2f221f5ba/kabupatenmajalengka-dalam-angka-2020.html.

Guha, S., Govil, H. dan Besoya, M. (2020), "An Investigation on Seasonal Variability between LST and NDWI in An Urban Environment Using Landsat Satellite Data", Geomatics, Natural Hazards and Risk, Vol.11, No.1, hal. 1319-1345. http://doi.org/10.1080/19475705.2020.1789762.

IPCC (2014), Climate Change 2014: Synthesis Report. Contribution of Working Groups I, II and III to the Fifth Assessment Report of the Intergovernmental Panel on Climate Change [Core Writing Team, R.K. Pachauri and L.A. Meyer (eds.)], Geneva, Switzerland. Diambil dari https://www.ipcc.ch/report/ar5/syr/.

Nadira, C., Saraswati, R. dan Wibowo, A. (2020), "Pengaruh Perubahan Tutupan Lahan Terhadap Fenomena Urban Heat Island di Kecamatan Cikarang Utara, Kabupaten Bekasi Tahun 2007 - 2018 Menggunakan Citra Landsat 5 dan 8", dalam Seminar Nasional Penginderaan Jauh ke-6 Tahun 2019, Departemen Geografi, Universitas Indonesia, Depok.

Nurhuda, A., Nurul Huda, D. dan Adhisurya, S. (2019), Penginderaan Jauh Untuk Analisis Spasial Temporal Suhu Permukaan Daratan di Kota Manado Tahun 2015 dan 2018.

Riyadi, F. dan Rahayu, S. (2019), "Hubungan Kerapatan Vegetasi dan Bangunan terhadap UHI (Urban Heat Island) di Kota Magelang", Ruang, Vol.5, No.2, hal. 8393. http://doi.org/10.14710/ruang.5.2.83-93.

Sobirin, S. dan Fatimah, R.N. (2015), "Urban Heat Island Kota Surabaya", Geo Edukasi, Vol.4, No.2. Diambil dari http://jurnalnasional.ump.ac.id/index.php/GeoEduka si/article/view/529.

Utomo, A.W., Suprayogi, A. dan Sasmito, B. (2017), "Analisis Hubungan Variasi Land Surface Temperature dengan Kelas Tutupan Lahan Menggunakan Data Citra Satelit Landsat (Studi Kasus : Kabupaten Pati)", Jurnal Geodesi Undip, Vol.6, No.2, hal. 71-80. 